School of Medicine, University of St Andrews, St Andrews, UK

2 Peninsula Medical School, University of Plymouth, Plymouth, UK

Correspondence to: M McCartney mm494@st-andrews.ac.uk Cite this as: BMJ 2021;374:n1996 http://dx.doi.org/10.1136/bmj.n1996 Published: 20 August 2021

\section{Long covid clinics should be run as research hubs}

\author{
Multidisciplinary care is not magically beneficial and can exclude patients from decisions \\ Margaret McCartney, ${ }^{1}$ Richard Byng ${ }^{2}$
}

The current and future effect of long covid-which includes both ongoing symptomatic covid-19 (4-12 weeks) and post-covid-19 syndrome (after 12 weeks) ${ }^{1}$-remains a staple in the media. A network of new clinics has been pledged in England amid widespread concern that many people have enduring symptoms. The National Institute for Health and Care Excellence (NICE) indicates that most people will recover, ${ }^{2}$ but also recommends that clinicians "consider referral" to "an integrated multidisciplinary assessment service" if people still have symptoms after four weeks. ${ }^{1}$ Is this the best way forward? We believe that substantial investment in specialist services to manage ongoing symptoms should proceed only under high quality research conditions.

Post-covid syndrome is unlikely to be a single entity and will vary according to whether people required invasive hospital treatment. There is probably a spectrum of underlying pathology, including self-limiting inflammation and damage to specific organs, continued viral presence, the sequelae of intensive care admission, autoimmune responses, and more general disruption of immune, inflammatory, endocrine, and neurological systems (comparisons have been made with chronic fatigue syndrome (CFS/ME)). ${ }^{3}$ Perspective is gained by considering what we know about recovery and rehabilitation after other serious infectious illnesses and our knowledge about the harms and benefits of diagnosis, treatment, and multidisciplinary teams.

The April 2021 survey by the Office for National Statistics shows $21 \%$ of people with confirmed covid-19 still have symptoms at 5 weeks and $13.7 \%$ at 12 weeks. ${ }^{4}$ A recent population based longitudinal study from Australia reported high rates of recovery among adults with confirmed covid- 19 (20\%, 80\%, $93 \%$, and $96 \%$ at $10,30,90$, and 120 days respectively). ${ }^{5}$ This indicates that, however distressing the symptoms, most people meeting NICE criteria for long covid are on a path, albeit often fluctuating, to natural recovery.

The figures for other infectious illnesses are comparable. For example, people aged over 50 with community acquired pneumonia report feeling breathless and weak for an average of 22 days and 24 days respectively; those with chronic obstructive pulmonary disease took an average of 52 days to recover, meaning that about half took longer. ${ }^{6}$ More than a third of low risk, ambulatory patients with community acquired pneumonia are still symptomatic 28 days later. ${ }^{7}$ Comparison between post-covid syndrome and CFS/ME is difficult as studies of CFS/ME commonly start with populations who have had symptoms for many months or years, but most show low rates of recovery. ${ }^{8}$
Concerns have been raised about enduring organ damage caused by covid-19, with some cardiac imaging studies of people who have recovered from covid-19 finding high rates of myocardial ${ }^{9}$ and organ inflammation. ${ }^{10}$ However, significantly disordered inflammatory response was found in those with and without symptoms, indicating a prolonged but not necessarily pathological response. ${ }^{11}$ Some studies suggest that myocarditis is relatively common after seasonal influenza, ${ }^{12}$ and $40-50 \%$ of patients admitted to intensive care with $\mathrm{H} 1 \mathrm{~N} 1$ associated acute respiratory distress syndrome reported exertional dyspnoea one year after discharge. ${ }^{13}$

Rather than seeing long covid as a new disease or set of syndromes, we could consider it in the context of problems seen routinely in general practice after infections or trauma-disrupting our ability to withstand stressors in an undifferentiated way, with unclear aetiology or prognosis, but nevertheless likely to resolve spontaneously. The value of investigation or drug treatment remains unclear and is likely to be limited.

Clinical services, often including multidisciplinary teams, are being set up to treat patients with ongoing symptoms from covid-19. They have been generally welcomed, but critical evaluation is important to ensure they serve patients well. Multidisciplinary care is not magically beneficial, is resource intensive, and can exclude patients from decisions. Timely use of the skills and knowledge of different specialist professionals is helpful, but improved decisions require an evidence base showing meaningful benefit for patients and cost effectiveness.

Without this evidence, there is the potential for harm through routine imaging and associated overdiagnosis, ineffective or harmful treatment, and wastage of resources through duplication of effort. ${ }^{14}$ Inconsistent advice is also a danger: without evidence based interventions people attending new clinics may be no better off, and may be worse off.

Despite this, there are no plans for these new services to be run as research hubs or be formally evaluated-a missed opportunity given the excellence achieved in drug treatment trials for covid-19. It may be that primary care could be resourced to deliver timely expert generalist care and social support more effectively than the multidisciplinary clinics. Assumptions about the benefit of new clinics, rather than critical evaluation and in-practice research, is likely to lead to poorer quality interventions and poorer information and support for a worried public.

Competing interests: We have read and understood BMJ policy on declaration of interests and have no interests to declare.

Provenance and peer review: Not commissioned; externally peer reviewed. 
1 National Institute for Health and Care Excellence. COVID-19 rapid guideline: managing the long-term effects of covid-19. 2021. https://www.nice.org.uk/guidance/ng188

2 NICE. NICE, RCGP, and SIGN publish guideline on managing the long-term effects of COVID-19. 2020. https://www.nice.org.uk/news/article/nice-rcgp-and-sign-publish-guideline-on-managingthe-long-term-effects-of-covid-19

3 Nalbandian A, Sehgal K, Gupta A, etal. Post-acute COVID-19 syndrome. Nat Med2021;27:601-15 doi: 10.1038/s41591-021-01283-z pmid: 33753937

4 Office for National Statistics. Prevalence of ongoing symptoms following coronavirus (covid-19) infection in the UK: 1 April 2021. https://www.ons.gov.uk/peoplepopulationandcommuni-

ty/healthandsocialcare/conditionsanddiseases/bulletins/prevalenceofongoingsymptomsfollowingcoronaviruscovid19infectionintheuk/1april2021

5 Liu B, Jayasundara D, Pye V, etal. Whole of population-based cohort study of recovery time from COVID-19 in New South Wales Australia. Lancet Reg Health West Pac 2021;12:100193. doi: 10.1016/j.lanwpc.2021.100193. pmid: 34189493

6 Wyrwich KW, Yu H, Sato R, Powers JH. Observational longitudinal study of symptom burden and time for recovery from community-acquired pneumonia reported by older adults surveyed nationwide using the CAP Burden of Illness Questionnaire. Patient Relat Outcome Meas 2015;6:215-23. doi: 10.2147/PROM.S85779. pmid: 26257528

7 Metlay JP, Atlas SJ, Borowsky LH, Singer DE. Time course of symptom resolution in patients with community-acquired pneumonia. Respir Med 1998;92:1137-42. doi: 10.1016/S0954-6111(98)90408-5 pmid: 9926169

8 Cairns R, Hotopf M. A systematic review describing the prognosis of chronic fatigue syndrome. Occup Med (Lond) 2005;55:20-31. doi: 10.1093/occmed/kqi013 pmid: 15699087

9 Puntmann VO, Carerj ML, Wieters I, etal. Outcomes of cardiovascular magnetic resonance imaging in patients recently recovered from coronavirus disease 2019 (covid-19). JAMA Cardiol 2020;5:1265-73. doi: 10.1001/jamacardio.2020.3557 pmid: 32730619

10 Dennis A, Wamil M, Alberts J, etalCOVERSCAN study investigators. Multiorgan impairment in low-risk individuals with post-COVID-19 syndrome: a prospective, community-based study. BM Open 2021;11:e048391. doi: 10.1136/bmjopen-2020-048391 pmid: 33785495

11 Doykov I, Hällqvist J, Gilmour KC, Grandjean L, Mills K, Heywood WE. The long tail of covid-19. The detection of a prolonged inflammatory response after a SARS-CoV-2 infection in asymptomatic and mildly affected patients. F1000Res 2020;9:1349.

doi: 10.12688/f1000research.27287.1 pmid: 33391730

12 Sellers SA, Hagan RS, Hayden FG, Fischer WA2nd. The hidden burden of influenza: A review of the extra-pulmonary complications of influenza infection. Influenza Other Respir Viruses 2017;11:372-93. doi: 10.1111/irv.12470. pmid: 28745014

13 Luyt CE, Combes A, Becquemin MH, etalREVA Study Group. Long-term outcomes of pandemic 2009 influenza A(H1N1)-associated severe ARDS. Chest 2012;142:583-92. doi: 10.1378/chest.11-2196 pmid: 22948576

14 Raine R, Wallace I, Nic a' Bháird C, etal. Improving the effectiveness of multidisciplinary team meetings for patients with chronic diseases: a prospective observational study. Health Serv Deliv Res 2014;2. doi: 10.3310/hsdr02370 pmid: 25642498

This article is made freely available for use in accordance with BMJ's website terms and conditions for the duration of the covid-19 pandemic or until otherwise determined by BMJ. You may use, download and print the article for any lawful, non-commercial purpose (including text and data mining) provided that all copyright notices and trade marks are retained. 